\title{
A nova classe média em I Love Paraisópolis: efeitos de sentido do social ${ }^{1}$
}

\author{
Conrado Moreira Mendes
}

Resumo: Neste artigo, procura-se compreender como se dá a construção discursiva da nova classe média (também chamada de nova classe C) na telenovela I Love Paraisópolis, à luz da semiótica de linha francesa. Para isso, toma-se como corpus o primeiro capítulo dessa produção, exibida pela Rede Globo em 2015. Nela, a personagem principal, Marizete, é moradora da favela de Paraisópolis em São Paulo. Nota-se que, nesse caso, a nova classe C não apenas faz parte, mas protagoniza a trama central. Assim, entende-se que a nova classe média tem seu locus privilegiado na favela/comunidade que intitula a telenovela em questão, da qual se analisam algumas cenas, tendo em vista os níveis narrativo e discursivo do percurso gerativo do sentido, de Greimas. Finalmente, levando em conta o modelo de Landowski (2002), que diz respeito aos modos de relação com a alteridade, procura-se demonstrar como se estabelecem as relações entre cidade e favela, considerando-se também alguns elementos da visualidade. Esse percurso permite compreender, assim, algumas tessituras do social em I Love Paraisópolis, entendendo-se, evidentemente, esse social como um efeito de sentido.

Palavras-chave: telenovela; nova classe média; semiótica de linha francesa.

Abstract: Brazil's new middle class in I Love Paraisópolis telenovela: the effects of meaning of society - This paper analyses the discursive construction of Brazil's new middle class (also called new class C) in the Brazilian telenovela (soap opera) I Love Paraisópolis, applying French semiotics as theoretical reference. Therefore, the first chapter of this telenovela, broadcasted by Rede Globo, in 2015, is taken as corpus. In the story, the main character, Marizete, lives in Paraisópolis favela, in São Paulo. It is noticeable, in this case, that the new class C does not play a peripheral part, but stars the central plot in the script. Thereby, acknowledging that the Brazil's new middle class has privileged locus in the favela the telenovela is named after, the scenes are analyzed concerning the narrative and discursive levels of the generative path of meaning. Finally, taking into account Landowski's (2002) model about the modes of relation to the otherness, it is presented how the relations between city and favela are established, also considering some elements of visual language. This pathway, therefore, allows to understand some of the social configurations in I Love Paraisópolis, considering, evidently, this society as an effect of meaning.

Keywords: telenovela; Brazil's new middle class; french semiotics.

1 Agradecemos ao Fundo de Incentivo à Pesquisa da PUC Minas (FIP/PUC-MG) pela bolsa concedida ao projeto de pesquisa 2016/10358 - S1, do qual este artigo é derivado, e à bolsista de Iniciação científica do projeto, Tamoni Monise Ferreira da Silva. 


\section{Introdução}

Neste artigo, procura-se compreender como se dá a construção discursiva da nova classe média (também chamada de nova classe C)² na telenovela / Love Paraisópolis. Para isso, toma-se como corpus o primeiro capítulo da trama escrita por Alcides Nogueira e Mário Teixeira, exibida pela Rede Globo, na faixa das 19h, de maio a novembro de 2015. No folhetim, a personagem principal, Marizete, interpretada por Bruna Marquezine, é moradora da favela de Paraisópolis em São Paulo. Nota-se, nesse caso, que a nova classe C não apenas faz parte da narrativa, mas protagoniza a história central. Com base na semiótica de linha francesa, interessa entender, assim, como se engendra, como efeito de sentido, essa nova classe média e com base em quais valores. Além disso, procura-se compreender como se constituem as práticas desse grupo social e, ainda, de que maneira se dão as relações/interações entre as classes sociais nessa telenovela ${ }^{3}$.

Cabe dizer, inicialmente, que a nova classe média passou a ganhar destaque nas telenovelas apenas recentemente. Podem-se citar Avenida Brasil (2012) e Cheias de Charme (2012) como as precursoras, no sentido de trazer a nova classe média para protagonizar as tramas (cf. MAURO, 2014). Isso se relaciona, sem dúvida, com o surgimento e a obtenção de relevância do referido grupo ${ }^{4}$.

De acordo com o documento Vozes da classe média, produzido pela Secretaria de Assuntos Estratégicos do Governo Federal, de 2002 para 2012, "35 milhões de pessoas entraram para a classe média" (BRASIL, 2012a, p. 7); esse estrato da população passou de $38 \%$ para $53 \%$ em 2012, o que equivale a 104 milhões de pessoas. Tais mudanças são consequência de um "conjunto de programas sociais reconhecidamente eficazes para reduzir a pobreza e promover a inclusão produtiva" (ibidem). Entre 2003 e 2010, foram criados mais de 14 milhões de empregos formais, o que fez com que a média do valor do salário do trabalhador aumentasse em $20 \%$

2 Utilizar-se-ão, indistintamente, os termos nova classe média e nova classe C.

3 Oliveira (2014, p. 184), no que diz respeito à relação entre as pessoas e as cidades, entende interação "como um ato transitivo entre sujeitos, é um ato que possibilita apreender, compreender e interpretar a relação que se estabelece entre cidade e população. A relação é de uma inter-ação tanto da cidade quanto da população, que são os sujeitos parceiros do próprio mecanismo operatório da construção do sentido". Prática, por sua vez, se refere a "um fazer cotidiano que caracteriza ações que se repetem, mas não de modo redundante que esvazia o sentido. Ao contrário, essas podem ser práticas de um indivíduo, de grupo social, ou, em maior escala, da população da cidade. A repetição de uma ação, de uma sequência delas, dá-se no eixo sintagmático em intervalos temporais e manifesta um modo de presença que é definido pela constância acional na cotidianidade. Os traços recorrentes mostram o que permanece na dinâmica transformacional e esses promovem a identificação da prática".

4 Ainda que, nos últimos dois anos, marcados por uma profunda crise político-econômica, o fenômeno da nova classe média esteja em franca decadência. De acordo com o jornal O Estado de S. Paulo, "de 2015 a 2017, 3,1 milhões de famílias da classe $C$, ou cerca de 10 milhões de pessoas, devem cair e engordar a classe D/E, aponta o estudo. 'A mobilidade que houve em sete anos (de 2006 a 2012) deve ser praticamente anulada em três (de 2015 a 2017). Estamos vivendo, infelizmente, o advento da ex-nova classe C', diz o economista Adriano Pitoli, sócio da consultoria e responsável pelo estudo" (CHIARA; PAPP, 2015, s/p). Não obstante, ainda que a ascensão da nova classe média brasileira tenha sido um fenômeno aparentemente efêmero, considera-se importante compreender sua construção simbólica/discursiva, inclusive, do ponto de vista histórico. 
Assim, esses elementos apontam para o surgimento de um novo grupo social, a chamada nova classe média: "como consequência dessa diminuição da pobreza e do crescimento acentuado da renda nos estratos mais pobres, uma grande parcela da população ascendeu a uma classe com renda intermediária" (BRASIL, 2012b, p. 6). Tais mudanças econômicas e sociais não poderiam deixar de ecoar, por conseguinte, no âmbito do simbólico; o documento oficial afirma: "pessoas das classes baixas [passaram a ocupar] espaços ou [ter] comportamentos que antes pareciam reservados às elites dos aeroportos aos shopping centers, das universidades ao horário nobre, do imaginário publicitário à agenda pública" (ibidem, p. 48).

Cumpre dizer, entretanto, que os principais autores (NERI, 2011; POCHMANN, 2012; SOUZA; 2010) que, na atualidade, tratam desse tema interpretam distintamente os dados que definem o que vem a ser ou não a chamada nova classe média ${ }^{5}$. Assim, não é ponto pacífico considerar a existência ontológica de uma nova classe $C$, ou que o Brasil tenha se tornado um país de classe média. De qualquer forma, ainda que haja diferentes pontos de vista acerca da chamada nova classe média, é inegável que a mídia se configure como "vitrine privilegiada", nas palavras de França e Corrêa (2012, p. 8), em que as mudanças sociais se dão a ver, "o que constitui uma razão a mais para considerá-la como importante objeto de pesquisa". Cabe salientar ainda que, pela epistemologia discursiva a que se filia (cf. BEIVIDAS, 2006, 2008), entende-se que a relação do homem com o mundo é sempre mediada pela linguagem - o mundo é, pois, efeito de sentido que emana das estruturas da língua(gem) - e que, semioticamente, o método de análise parte sempre do texto e, a partir desse, chega-se ao extratextual/contexto (cf. BARROS, 2002).

5 Entre os três autores aludidos que tratam do tema da nova classe média, Neri (2011, p. 82) é o mais otimista. Para esse autor, o cálculo para classificar alguém como pertencente à classe $C$ consiste em considerar a renda total de todos os membros da família na faixa que vai de $\mathrm{R} \$ 1.200,00$ a $\mathrm{R} \$ 5.174,00$. Para Neri (ibidem, p. 83-84), “ $80 \%$ das pessoas no mundo vivem em países com níveis de renda per capita menores que o brasileiro [e que, dessa forma,] a nossa classe média não seria diferente daquela observada no mundo, usando os mesmos métodos". Pochmann (2012), por sua vez, diferentemente de Neri (2011), que afirma que o Brasil é um país de classe média, defende que não há uma nova classe média brasileira, mas uma melhora das condições de vida das classes trabalhadoras: "Seja pelo nível de rendimento, seja pelo tipo de ocupação, seja pelo perfil e atributos pessoais, o grosso da população emergente não se encaixa em critérios sérios e objetivos que possam ser claramente identificados como classe média. Associam-se, sim, às características gerais de classes populares, que, por elevar o rendimento, ampliam imediatamente o padrão de consumo" (POCHMANN, 2012, p. 10). Para esse autor, portanto, não se trata de uma nova classe média, mas tão somente de uma classe trabalhadora com maior poder de compra. Souza (2010), ainda mais crítico que Pochmann (2012), vê com maus olhos a nomenclatura nova classe média. Para o autor, não se negam inúmeros avanços sociais, no entanto, trata-se de uma meia-verdade considerar que somente o fator renda e o maior poder de consumo possam ser suficientes para classificar um indivíduo como pertencente à classe média. Para esse autor, a meia-verdade de que não se fala é o aspecto imaterial do pertencimento à classe média, ao aspecto simbólico que não se refere apenas à renda, o que "reside em literalmente não ver o mais importante, que é transferência de valores imateriais na reprodução das classes sociais e de seus privilégios no tempo. Reside em não perceber que, mesmo nas classes altas, que monopolizam o poder econômico, os filhos só terão a mesma vida privilegiada dos pais se herdarem também o "estilo de vida", a "naturalidade" para se comportar em reuniões sociais, o que é aprendido desde tenra idade na própria casa com amigos e visitas dos pais (SOUZA, 2010, p. 23). Assim, para Souza (ibidem), considerar uma classe trabalhadora cujo poder de compra vem aumentando desde 2002 como nova classe média tratar-se-ia, em essência, de um instrumento ideológico de perpetuação das diferenças sociais e, consequentemente, da manutenção da hegemonia das classes dominantes. 
Assim, entendendo que a nova classe média tem seu locus privilegiado na favela que dá nome à trama, analisam-se algumas cenas do primeiro capítulo dessa telenovela levando-se em conta os níveis narrativo e discursivo (em específico, temas e figuras) do percurso gerativo do sentido ${ }^{6}$. Finalmente, tomando como apoio o modelo de Landowski (2002), que diz respeito aos modos de relação com a alteridade, constituído pelos termos assimilação, exclusão, admissão e segregação, procura-se demonstrar como se dão as relações entre cidade e favela, ora por meio de uma relação, ora por outra, considerando-se, ainda, alguns elementos da linguagem visual. Esse percurso permite, assim, compreender algumas tessituras do social em I Love Paraisópolis, entendendo-se, evidentemente, esse social como um efeito de sentido.

\section{De Paraisópolis para Nova lorque}

O primeiro capítulo de I Love Paraisópolis começa com cenas aéreas de Nova lorque, para onde Marizete e sua amiga Danda se mudam para tentar uma vida melhor. O enunciador da telenovela é didático, pois, além exibir imagens conhecidas/estereotipadas como a Estátua da Liberdade e o Central Park, inscreve-se, no canto superior esquerdo na tela, o nome da cidade em questão, conforme se vê a seguir (Fig. 1):

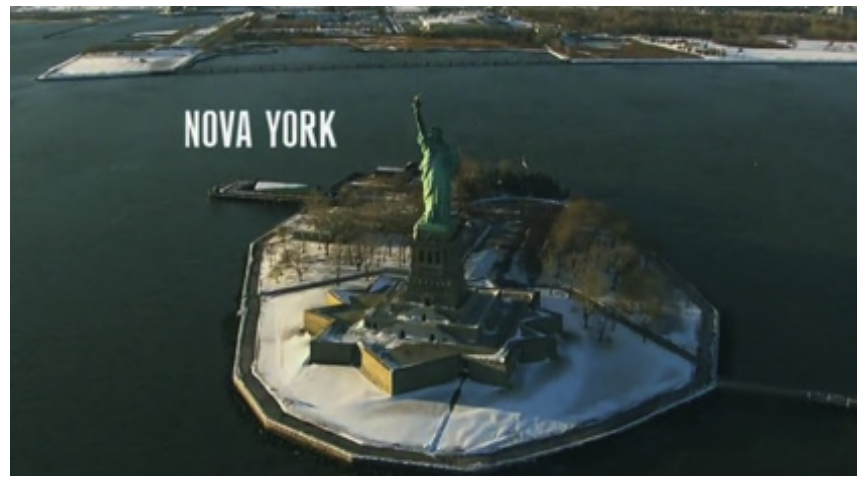

Fig.1. Vista aérea de Nova lorque. Fonte: Gshow ${ }^{7}$

Narrativamente, Marizete é um sujeito em privação que quer ${ }^{8}$ se apropriar do objeto-valor (OV) "melhores condições de vida" para poder doá-lo a Eva, sua mãe de

6 A semiótica concebe, metodologicamente, a produção de sentido do plano do conteúdo dos textos a partir do percurso gerativo do sentido, formado pelos níveis fundamental (ou profundo), narrativo e discursivo, ou seja, tal percurso vai do patamar mais simples e abstrato ao mais complexo e concreto (Cf. GREIMAS; COURTÉS, 2008, p. 232-235).

7 Todas as imagens de / Love Paraisópolis são quadros/frames capturados a partir da exibição da telenovela no site oficial da novela, disponível em: <http://gshow.globo.com/novelas/i-love-paraisopolis/>. Acesso em: 15 Jul. 2016.

8 Referentes à semântica narrativa, as modalidades alteram as relações dos sujeitos com os valores inscritos nos objetos. O dever e o querer são modalidades virtualizantes, o poder e o saber são modalidades atualizantes e o fazer e o ser são modalidades realizantes (Cf. GREIMAS; COURTÉS, 2008, p. 314-316). Conforme os autores do Dicionário de semiótica, modalidades e modalizações serão grafadas em itálico. 
criação, que também é mãe de Danda, melhor amiga da protagonista. Num diálogo entre as amigas-irmãs, Marizete diz: "Eu tenho que retribuir tudo o que a sua mãe fez por mim". Assim, ela é um sujeito que queria e devia ajudar a mulher que a adotou. Nota-se que, já no primeiro capítulo, a protagonista é guiada por valores altruístas, o que é característico do gênero melodramático em que se assenta a telenovela. Nesse sentido, para Huppes (2000, p. 33), há dois temas fundamentais no melodrama: a reparação da injustiça e a busca da realização amorosa, elementos recorrentes até os dias de hoje nas telenovelas. Além disso, para Thomasseau (2005, p. 36), no melodrama, ocorre, em geral, o desmascaramento do vilão pelo herói, de cuja estrutura se depreende uma axiologia moralizante. Desse modo, no final da história, os valores eufóricos são sancionados positivamente, e os disfóricos, negativamente. Em / Love Paraisópolis, não é diferente ${ }^{9}$.

Além de querer e dever ajudar a mãe de criação, o sujeito "Marizete" também é modalizado por um saber: uma ex-moradora de Paraisópolis, chamada Lindalva, aparentemente, conseguiu vencer na vida nos EUA. Numa da cenas, Danda fala com Marizete: "Olha aqui ela esquiando em Aspen. Ela tá tão bem. Quando a Lindalva saiu daqui saiu sem falar uma palavra de inglês, com a roupa do corpo". E então o enunciador de I Love Paraisópolis revela, no entanto, tratar-se de uma mentira o fato de Lindalva ser bem sucedida em seu intento de obter uma vida melhor nos EUA: a personagem tira uma selfie tendo como segundo plano montanhas nevadas quando, na verdade, simula estar numa estação de esqui, usando como pano de fundo um cartaz de viagem no qual se estampavam as tais montanhas, como se vê a seguir (Figs. 2 e 3):

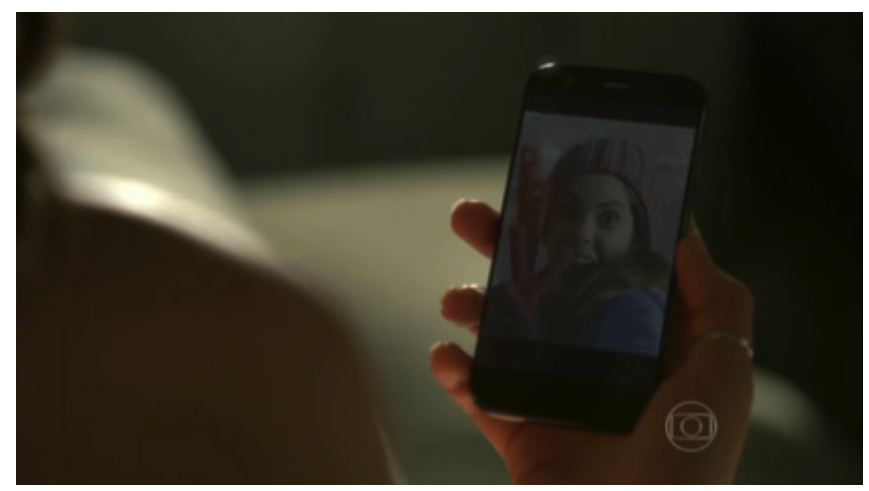

Fig. 2. Lindalva em estação de esqui. Fonte: Gshow

9 Não é o objetivo deste trabalho, entretanto, observar como, narrativamente, I Love Paraisópolis se constrói como gênero melodramático/folhetinesco. 


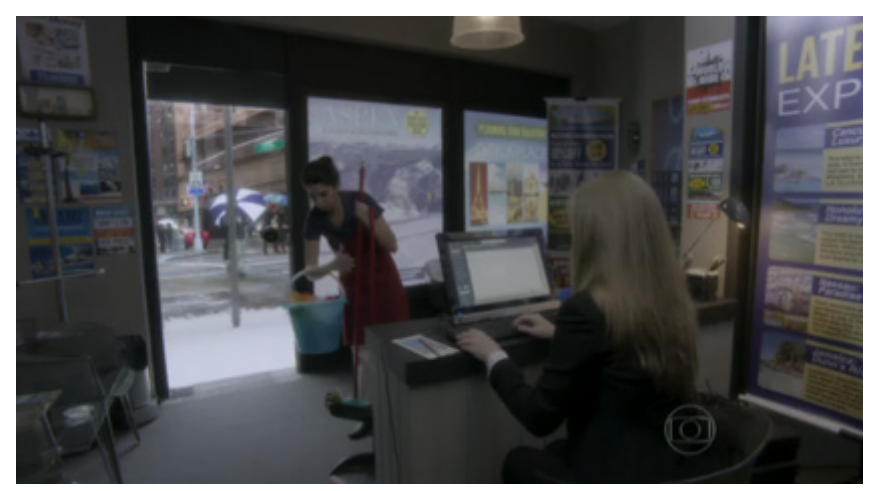

Fig. 3. Desmascaramento de Lindalva. Fonte: Gshow

Assim, o sucesso de Lindalva nos EUA parecia mas não era verdadeiro: era, do ponto de vista da veridicção, mentiroso ${ }^{10}$.

Além de querer uma vida melhor, dever conquistá-la para doar à mãe de criação, o sujeito "Marizete" sabia supostamente como obtê-la, ou seja, fazer como Lindalva, ou seja, ir para os Estados Unidos. Finalmente, o sujeito "Marizete" se mune de um poder: o dinheiro para a passagem aérea e o suficiente para passar alguns dias nos EUA até conseguir um emprego, obtido por meio da venda de uma casa. Porém, já nas primeiras cenas em Nova Iorque, Marizete e sua amiga perdem o dinheiro e os documentos e, depois de alguns dias, são obrigadas a voltar para Brasil, falhando na tentativa de entrar em conjunção com o objeto-valor "melhores condições de vida" para, enfim, poder doá-lo à mãe de criação.

\section{Paraisópolis, actante coletivo}

Depois de ter todo o dinheiro e documentos furtados em Nova lorque, faz-se um salto temporal para uma semana antes, quando Marizete diz: "De Paraisópolis para Nova lorque. Quer saber como a gente veio parar aqui?". Apresenta-se, na sequência, uma cena que mostra Marizete, conduzindo uma bicicleta com uma cesta, bonita, sorridente, com maquiagem leve e penteada, passeando por Paraisópolis, contemplando a favela (Figs. 4 e 5):

10 A partir da relação entre as modalidades veridictórias - o ser e o parecer - dispostas no quadrado veridictório, depreedem-se os seguintes efeitos: aquilo que é e parece é verdadeiro; aquilo que não parece e não é é falso; o que é mas não parece é secreto e, finalmente, o que parece mas não é é mentiroso (Cf. GREIMAS; COURTÉS, 2008, p. 332-333). 


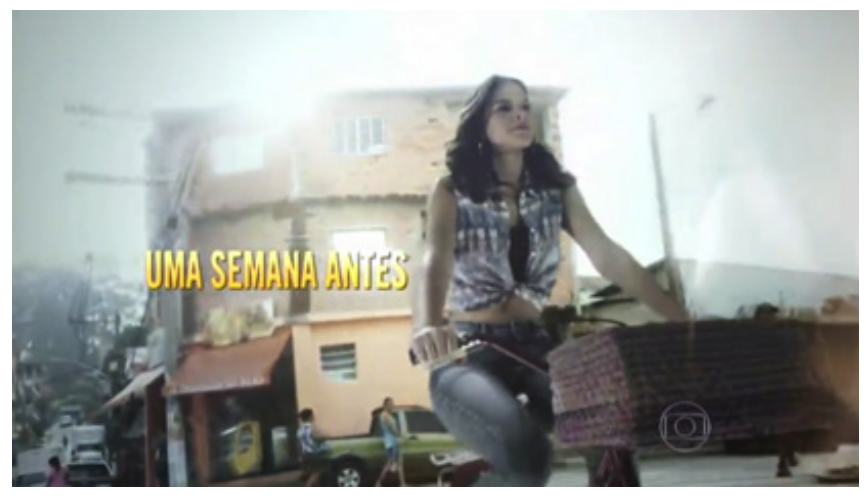

Fig.4. Marizete de bicicleta em Paraisópolis. Fonte: Gshow

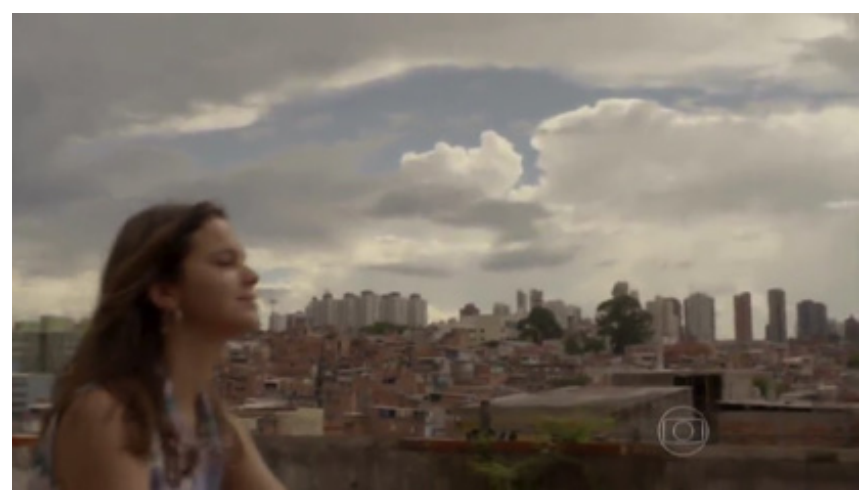

Fig.5. Marizete de bicicleta em Paraisópolis (2). Fonte: Gshow

A personagem, então, se apresenta:

Eu trabalho desde os meus treze anos. Já fui babá, faxineira, ajudei na feira, já fiz carreto... Paraisópolis tem quase um milhão de metros quadrados. Aqui vivem mais de 100 mil pessoas. Todo mundo querendo ser feliz. Se a gente chegou até aqui, construiu uma cidade dentro da cidade, é que a gente merece uma chance. Na verdade, o lugar que a gente nasceu nunca sai da gente.

Assim, ao ator do discurso Marizete, ao realizar uma série de ações ("já fui babá, faxineira, ajudei na feira, já fiz carreto"), subjaz um sujeito do fazer. Esse sujeito coloca-se como parte de um actante coletivo Paraisópolis, conforme se destaca a seguir: "Paraisópolis tem quase um milhão de metros quadrados. Aqui vivem mais de 100 mil pessoas. Todo mundo querendo ser feliz. Se a gente chegou até aqui, construiu uma cidade dentro da cidade, é que a gente merece uma chance" (grifos nossos). Desse modo, ao se projetar no discurso como um nós exclusivo (eu + eles) (Cf. FIORIN, 2005a), o narrador "Marizete" 
coloca-se como parte de uma coletividade, à qual subjaz um actante também coletivo. Greimas e Landowski (1976, p. 96-99) concebem o actante coletivo como indivíduos que partilham com outros um certo papel temático (no caso, o morador de Paraisópolis). Tal actante é suscetível de individuação, ao mesmo tempo em que se funde num todo. Salientam os autores que o actante coletivo é subsumido pela figura do(s) ator(es) também coletivo(s).

Assim, esse actante coletivo (Paraisópolis), apesar de realizar outros programas narrativos (de uso): "chegou até aqui, construiu uma cidade dentro da cidade", não conseguiu ainda realizar o programa narrativo (PN) de base "ser feliz": "todo mundo querendo ser feliz; a gente merece uma chance". Trata-se esse actante coletivo, portanto, de um sujeito virtualizado, que quer mas não pode (ser feliz). Assim, apesar de a ideologia se manifestar de forma mais patente no nível discursivo (Cf. FIORIN, 2005b), nota-se, já no nível narrativo, uma impossibilidade de realizar seu PN de base desse actante coletivo Paraisópolis.

Da outra ponta da narrativa, aparece o sujeito "Benjamin" que, assim como Marizete também é guiado por valores altruístas. Benjamin é arquiteto, rico, loiro, bonito e autor de um projeto de reurbanização de Paraisópolis. No primeiro capítulo, Benjamin se refere algumas vezes a esse projeto: "O projeto de reurbanização de Paraisópolis"; "Essa aqui é nossa arquitetura. E é com isso que a gente tem que se preocupar: imaginar um mundo melhor". Benjamin, com sua mãe, Soraya, detém mais da metade das ações da empresa da família, a Pilartex: "Soraya, você precisa entender: o projeto de reurbanização de Paraisópolis pode mudar a vida de muita gente"; "Eu e você juntos temos a maior parte das ações da Pilartex". Assim, ao ator do discurso Benjamin, subjaz um sujeito que quer "mudar a vida de muita gente", que sabe, uma vez que é um arquiteto renomado e pode, já que, junto com a mãe, possui a maior parte das ações da empresa responsável pela realização do projeto. Logo, em termos narrativos, Benjamin é um sujeito atualizado (S2), cuja ação em relação ao actante coletivo/sujeito virtualizado Paraisópolis (S1) é fazer-ser, ou seja, fazer com que S1 entre em conjunção com o OV "urbanização / melhores condições de vida" e, em última instância, com o OV "felicidade".

Assim, pelo discurso de I Love Paraisópolis, depreende-se uma estrutura narrativa segundo a qual Paraisópolis, actante coletivo, é um sujeito virtualizado e, portanto, incapaz de realizar a principal ação de sua narrativa a não ser por meio de um outro sujeito que pode e sabe fazer por ele. Desse modo, a favela/comunidade Paraisópolis, entendida como efeito de sentido e habitada em sua maioria por indivíduos da nova classe média brasileira, não é modalizada por um saber nem um poder, apenas um querer. Narrativamente, esse sujeito não age, mas depende de um outro sujeito, figurativizado pelo branco, rico, heterossexual, morador do bairro nobre, para realizar por ele a ação transformadora. 


\section{Temas e figuras em Paraisópolis}

Visando a compreender como essa nova classe média se constitui como discurso, identificaram-se, principalmente, temas e figuras ${ }^{11}$ ligados ao consumo e, em menor grau, à escolaridade. O primeiro percurso temático-figurativo, nesse caso, é aquele ligado à compra da casa própria. Na trama, Marizete faz um financiamento para comprar uma casa para a mãe de criação. A personagem afirma: "Eu acabei de comprar uma casa. Eu paguei a entrada dessa casa. Eu tenho 20 anos de prestação"; em outro momento, diz: "Você esqueceu que eu comprei uma casa para a tia Eva?". Desse modo, subjacente ao tema da compra da casa própria, está o tema do crédito. Segundo o Dicionário Houaiss da Língua Portuguesa, crédito significa: "constituir(-se) como credor de determinada quantia (respectivamente, atribuindo-Ihe dívida ou reconhecendo-se devedor); acreditar". Dessa forma, as instituições financeiras governamentais ou não (no texto em análise, isso não se esclarece) oferecem a possibilidade, por exemplo, de que se comprem imóveis por meio do crédito, ou seja, tais instituições financeiras quitam o valor da dívida e aquele que contraiu o crédito passa a dever ao banco. A segunda definição do termo, "acreditar", é útil para se compreender semioticamente essa relação: estabelece-se um contrato fiduciário entre aquele que dá por empréstimo (a instituição financeira) e aquele que toma por empréstimo, baseado na fidúcia, ou seja, o banco crê que quem pegou emprestado possa pagar as parcelas do financiamento. Como os bancos não são conhecidos exatamente pela benevolência, infere-se que, se alguém realiza um financiamento, esse alguém pode fazê-lo. Assim, a possibilidade de crédito indica um aumento de poder de compra/renda de um grupo social, que, muito em função disso, passou a ser conhecido como nova classe média.

Outro percurso temático encontrado no primeiro capítulo da telenovela em análise é o da escolaridade. Marizete, como representante desse estrato social, além da possibilidade de compra, também frequentou a escola. Danda, ao conversar com Marizete, diz para a amiga: "As pessoas esperam mais de você porque você nunca parou de estudar". O fato de nunca ter parado de estudar indica, dessa maneira, que a personagem é escolarizada/ letrada. Numa entrevista de emprego, o contratante afirma: "O currículo é muito bom. Bom demais para esse cargo". Assim, infere-se que o alargamento do poder de compra encontra-se, de certa forma, atrelado ao aumento do nível de letramento/escolaridade dessa classe ascendente ${ }^{12}$.

11 Segundo Fiorin (2006, p. 90), "podem-se revestir os esquemas narrativos abstratos com temas e produzir um discurso não figurativo ou podem-se, depois de recobrir os elementos narrativos com temas, concretizá-los ainda mais, revestindo-os com figuras". Desse modo, temas são elementos linguísticos de abstratos, de natureza conceitual, que organizam as figuras, que, por sua vez, são elementos de maior concretude e que se referem a elementos do mundo natural. Temas e figuras se disseminam nos textos, criando percursos temáticos e figurativos, a partir dos quais se depreende uma coerência, um plano de leitura ou, em outros termos, uma isotopia.

12 Como o corpus de análise deste trabalho é o primeiro capítulo de / Love Paraisópolis, não seria semioticamente pertinente trazer informações que o extrapolem. Salienta-se, no entanto, que, no capítulo 15, a personagem Marizete afirma: "eu tenho dois cursos técnicos", fato que apenas corrobora a consideração feita acima, a respeito do aumento de nível de educação formal da nova classe média. 
Outro percurso temático que se depreende é o da busca pela estabilidade laboral. Em uma das primeiras cenas do capítulo, Marizete aparece trabalhando como chapeira e Danda como garçonete na padaria de Paraisópolis. Para defender a melhor amiga do assédio de um freguês, Marizete agride o cliente e, por isso, ambas perdem o emprego. A mulher do patrão, depois da confusão que se instalou ali, diz: "As duas estão no olho da rua! E por justa causa. Sem direito a nada". No caminho para casa, Marizete fala com Danda: "As duas na rua de novo. Como que eu vou me virar?". Pode-se deduzir pelo elemento linguístico "de novo" que não era a primeira vez que eram demitidas. Depreende-se, assim, o tema do desemprego/instabilidade laboral. Marizete, então, começa a distribuir currículos e consegue trabalho como faxineira numa grande empresa, a Pilartex, de propriedade de Benjamin, que será par romântico da moça, e de sua família. Na entrevista de emprego, Marizete fala com o contratante: "Eu estou tendo dificuldade para encontrar emprego. Eu garanto que, se você me contratar, eu vou ser a melhor faxineira que já trabalhou aqui nessa firma. Te garanto que o senhor não vai se arrepender". Assim, apesar de ter um currículo superior ao que a vaga exigia, ela aceita a vaga em função da estabilidade que o emprego the oferece. Já trabalhando como faxineira, ela fala ao celular com a mãe de criação: "Tia, eu não tenho do que reclamar. Eu aceitei porque eu quis. Carteira assinada. Fundo de garantia, $13^{\circ} \ldots$ E eu não vou ter que vender a casa". Assim, entende-se que o tema do emprego/estabilidade laboral é pré-requisito, nesse caso, para a manutenção do consumo, ou seja, a continuidade da compra da casa própria por meio de um financiamento.

Nota-se, ainda, por meio da linguagem visual, o tema da viagem a um país estrangeiro, já que, logo nas primeiras cenas, aparecerem Marizete e Danda em Nova lorque. Viajar para um país estrangeiro, ainda que o objetivo seja a imigração ilegal ou o subemprego, pressupõe igualmente o tema do consumo. É preciso poder comprar uma passagem aérea e ter uma reserva financeira para os primeiros dias. Várias cenas da telenovela figurativizam/iconizam o tema da viagem para um país estrangeiro, tema esse que se inscreve num tema mais amplo, que é o consumo, como, por exemplo, por meio de tomada aérea da Estátua da Liberdade, do Central Park, imagens do Grand Central Terminal e também imagens de Marizete e Danda brincando na neve, conforme mostram as imagens a seguir (FIGS. 6, 7, 8 e 9):

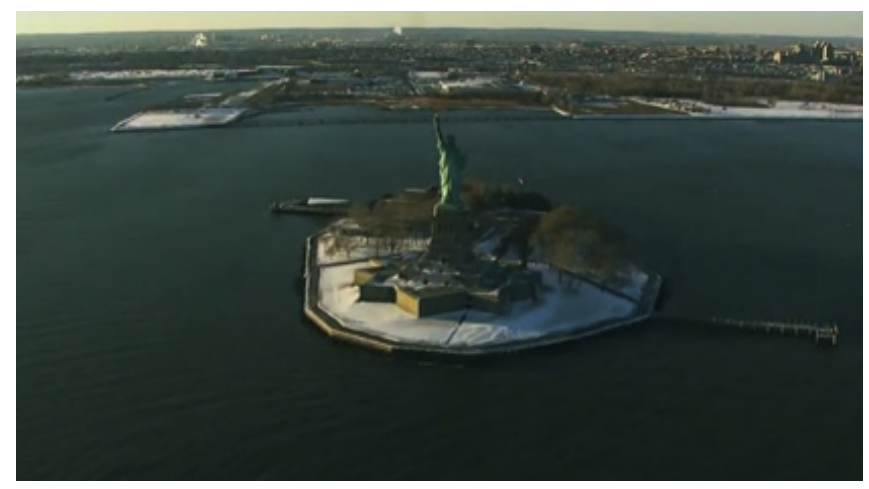

Fig. 6. Tomada aérea da Estátua da Liberdade. Fonte: Gshow 


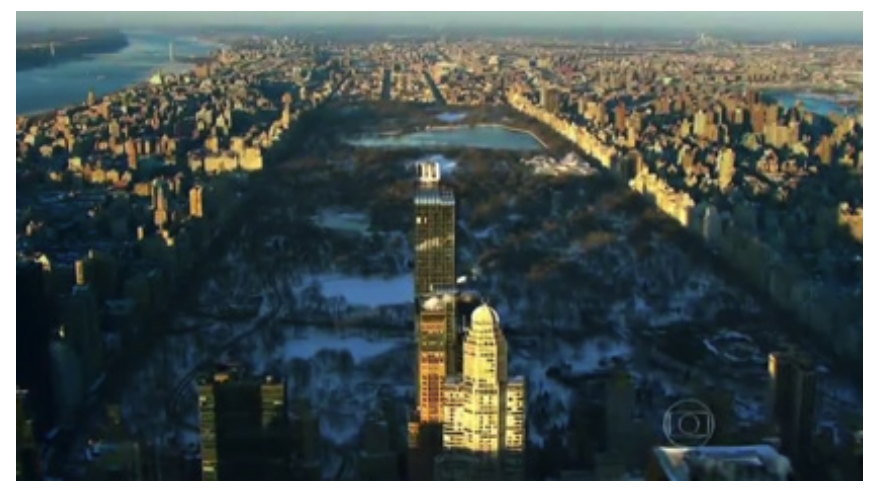

Fig.7. Tomada aérea do Central Park. Fonte: Gshow

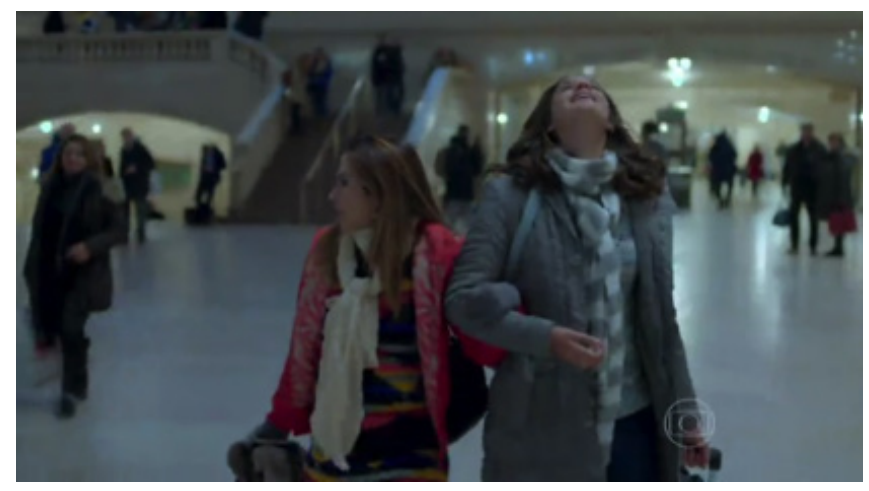

Fig.8. Marizete e Danda no Grand Central Terminal. Fonte: Gshow

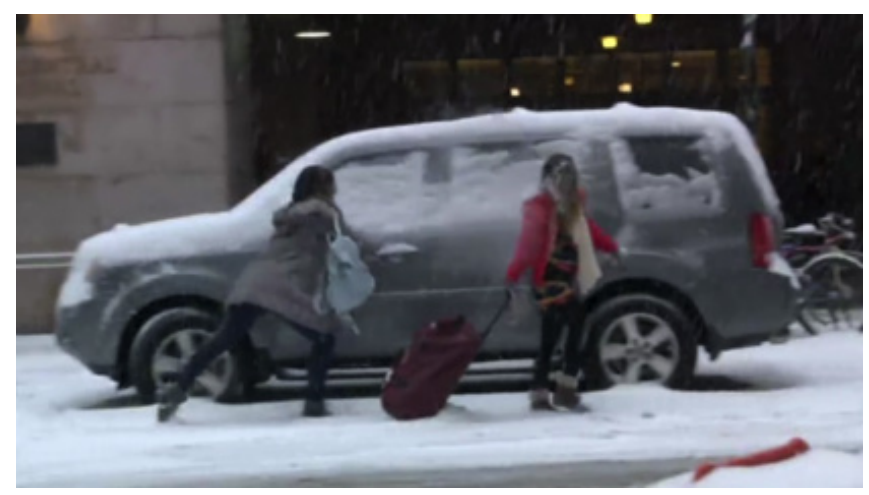

Fig.9. Marizete e Danda brincando na neve. Fonte: Gshow

Ainda considerando o tema do consumo, em uma cena do primeiro capítulo da telenovela em análise, Jurandir, ex-marido de Eva, tentando reconquistá-la, sobe 
no telhado da casa dela para fazer uma instalação ilegal de TV a cabo. Nesse momento, ele afirma: "Agora a Vivinha ${ }^{13}$ vai ter TV a cabo de qualidade. Mais de 120 canais." A partir do exposto, pressupõe-se que a possibilidade de assistir a mais de 100 canais é valorizada euforicamente por aquele grupo social, ainda que não se trate de uma instalação legal. Nota-se, assim, um alargamento do horizonte simbólico de um grupo social que não mais se contenta em assistir meia dúzia de canais abertos. Nesse sentido, a possibilidade mesma de poder assistir a canais segmentados e conteúdos que se destinavam à classe média dita "tradicional" promove um acesso a conteúdos de bens simbólicos, antes inacessíveis a esse grupo.

O último tema de que se vai tratar é o da luta marcial krav magá. Em uma das cenas, Marizete aparece golpeando um saco de pancada. Ximena, então se aproxima e diz: "Tá batendo forte, hein, Marizete. Esse krav magá tá te fazendo bem". Krav magá, que do hebraico significa combate de contato, consiste em técnicas de luta, defesa contra armas, torções, entre outros. Criado em Israel, esse é um tipo de arte marcial ainda pouco comum no Brasil. Assim, o krav magá, nessa cena enunciativa, tem um duplo efeito de sentido. O primeiro está ancorado na ideia de concessão (cf. ZILBERBERG, 2011), isto é, instaura o inesperado, pois não se imagina, a princípio, que um morador de comunidade/favela seja praticante de uma luta pouco convencional no Brasil. O segundo efeito de sentido que se depreende disso é o do alargamento do horizonte simbólico da nova classe $\mathrm{C}$, o qual, como se viu, está relacionado com o aumento do poder de compra desse grupo.

Assim, por meio dos percursos temático-figurativos aqui arrolados, pode-se dizer que essa nova classe média se constrói, pelo discurso, a partir do tema da compra e do crédito como, por exemplo, no caso do financiamento da casa própria e da viagem internacional. Verificou-se ainda que, com esse aumento do crédito/poder de compra, encontra-se o tema da escolaridade, ainda que em menor grau. Assim, ascende-se socialmente não somente pelo consumo, mas também pela educação. Esses elementos apontam, assim, para o alargamento do horizonte simbólico dessa classe social, como se verificou pelo tema da TV a cabo ou da luta marcial pouco convencional. Desse modo, o acesso a esses bens materiais ou simbólicos pela via do consumo e pela via da educação acabam por constituir algumas práticas semióticas da nova classe C em I Love Paraisópolis.

\section{Favela e cidade: imbricações e tensões}

O último tópico deste trabalho se presta a discutir as formas de relação entre favela e cidade, com base na relação dos atores do discurso desses/nesses lugares, a partir do modelo proposto por Landowski (2002). Para o autor, há quatro modos de tratamento do si para com o outro: assimilação, exclusão, admissão e segregação, dispostos no quadrado semiótico a seguir:

13 Apelido para Eva. 


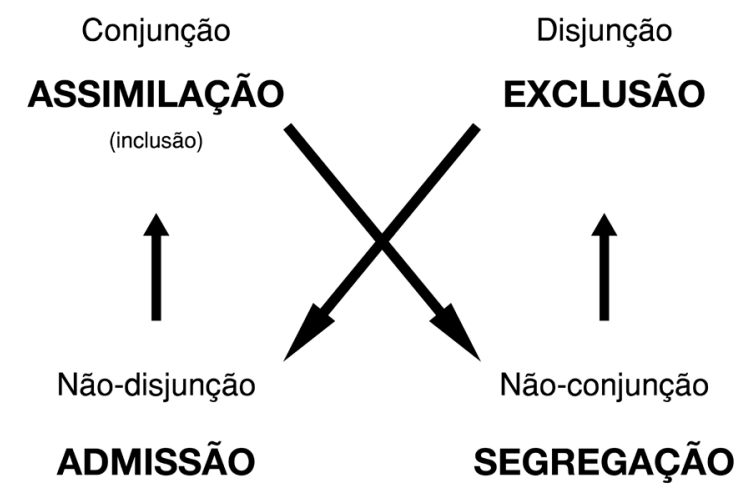

Quadro 1. Relações entre o si e o outro. Fonte: LANDOWSKI, 2002, p. 15.

O modelo de Landowski contempla, dessa maneira, as formas como uma identidade se relaciona com uma alteridade. No caso da assimilação, o outro perde suas características de outro e passa a adotar as convenções, hábitos, costumes, características, etc. do novo grupo. Deixa, assim, de ser outro e torna-se, com isso, o um. Em exemplo dado pelo autor, no caso da França, são os imigrantes que tentam se adequar ao máximo ao estilo de vida francês. Em última instância, esse imigrante nega seus hábitos e sua cultura de origem para ser assimilado, passando, desse modo, a parecer francês. A negação da assimilação é a segregação. Nesse caso, dois ou mais grupos coabitam a mesma sociedade, mas não existem trocas ou contato entre eles; o autor dá como exemplo, nesse caso, o apartheid. O termo contrário à assimilação é a exclusão. Trata-se, tomando como base a perspectiva de Barros (2015) a respeito do discurso intolerante, daqueles casos em que o sujeito é sancionado por não ter cumprido um dever social. Sanciona-se, negativa e pragmaticamente, por exemplo, com a prisão ou a morte, pelo fato de a presença da alteridade ser intolerável. Por fim, a negação da exclusão é a admissão. A partir dela, reconhecem-se as diferenças que fazem do outro o outro, no entanto, admitem-se tais diferenças. O exemplo que Landowski dá, nesse caso, é o do trabalhador português na França, cujas diferenças em relação aos franceses não são tão grandes como as do negro delinquente e, por isso, trata-se de uma presença admitida.

Assim, considerando o corpus deste trabalho, parte-se do princípio de que Paraisópolis é, na novela, o locus privilegiado da nova classe média, em função do que já se expôs em seções anteriores, e a cidade, figurativizada pelo bairro do Morumbi, o lugar da elite. Assim, a partir desses lugares, pretende-se compreender como se dão aí as relações sociais.

Logo nas primeiras cenas do primeiro capítulo de I Love Paraisópolis, é apresentada a personagem Soraya. Moradora do Morumbi, mãe de Benjamin, ela afirma: "Odeio tudo que vem dessa favela. Menos o pão. Tenho que admitir que eles fazem o melhor pão da cidade". Na cena seguinte, diz: "Por mim, eu jogava uma bomba nesse lugar". 
Assim, Soraya confessa não gostar da favela, mas gosta (admite) do pão que vem de lá: cria-se, assim, uma zona de passagem entre cidade e favela. Além disso, apesar de querer destruir a favela, não pode. Dessa forma, o sujeito que deseja a exclusão é apenas virtualizado, pois, na prática, tem que admitir o outro, mesmo que a contragosto. Ainda considerando essa personagem, em uma das cenas, faz-se um flashback, quando Benjamin se lembra de quando sua mãe o havia deixado num colégio interno e um dos motivos, segundo sua mãe, era sua aproximação com "aquela favela pestilenta". Nesse caso, é a exclusão que se realiza, uma vez que ela tira o filho de circulação, excluindo-o, para que não tenha contato com pessoas da favela.

Em outra cena, Benjamin e sua namorada Margot, pertencentes ao núcleo rico da novela, estão presos no trânsito, a caminho de uma reunião importante. Instala-se, então, um diálogo entre Margot, Benjamin e a taxista sobre a possibilidade de fazerem um atalho, passando por Paraisópolis, para que conseguissem chegar a tempo:

\author{
Margot: "Ainda vai demorar muito, motorista?" \\ Taxista: "Olha, se a senhora quiser, a gente pode cortar caminho pela favela". \\ Benjamin: "Acho uma ótima ideia". \\ Taxista: "Tem medo, não, moço?" \\ Benjamin: "Medo de quê?" \\ Taxista: "Todo mundo acha que favelado é ladrão". \\ Benjamin: "Isso é preconceito, bobagem. Acho que você deve cortar caminho \\ sim, contanto que chegue a tempo".
}

Na cena transcrita, Benjamin, ao negar a ideia de que "todo favelado é ladrão", coloca-se no papel de "Sr. Todo Mundo", aquele que, segundo Landowski (2002, p. 6-7), não exclui, mas admite o outro na sua diferença, podendo, no limite, assimilar o diferente, fazendo dele um igual. No caso em pauta, Benjamin não vê problemas na relação entre a cidade e a favela; ele admite passar por dentro dela "contanto que chegue a tempo". Conforme se viu na análise referente ao nível narrativo, Benjamin é autor de um projeto de reurbanização de Paraisópolis. Assim, do ponto de vista do modelo de Landowski, reurbanizar, nesse caso, tratar-se-ia de impor à favela uma forma de urbanização que é própria da cidade. Isso corresponderia ao apagamento de uma primeira forma de urbanização, a da favela, e a imposição de uma segunda forma de urbanização, a da cidade. Assim, a cidade passaria a assimilar a favela, desde que essa deixasse de ser favela e passasse a adotar as formas urbanísticas/formas de vida da cidade. Nesse caso, a assimilação dar-se-ia por meio do apagamento da diferença da favela em relação à cidade.

Ao entrar em Paraisópolis, o carro da taxista é parado por Ximena, que se dirige à motorista: "Passou por aqui por quê?", ao que a outra responde: "Para cortar caminho". Ximena, então, vai pedir autorização para que o táxi passe por dentro da favela a Grego que, segundo a taxista, "é o mandachuva: manda na chuva, manda no sol; obedece quem 
tem juízo". Depois de inspecionar o carro, Grego permite a passagem. Nesse momento, dá-se também a admissão, mas agora quem admite é a favela: essa passa à condição de identidade, enquanto aquela, à de alteridade. Assim, invertendo-se os pontos de vista, da favela para a cidade, também se admite a diferença.

Na sequência da cena, a personagem Rosicleia leva um carro aberto cheio de turistas brancos estrangeiros - o "Sr. Todo Mundo", no dizer de Landowski (2002) - para conhecer e tirar fotos da favela e de seus habitantes. Para o Sr. Todo Mundo, "administrado em dosagem moderada, o exotismo pode efetivamente ter seu encanto, como espetáculo a ser visto no local" (ibidem, p. 6). Na cena, os estrangeiros saem do carro aberto e fotografam a favela, conforme se vê a seguir (Figs. 10 e 11):

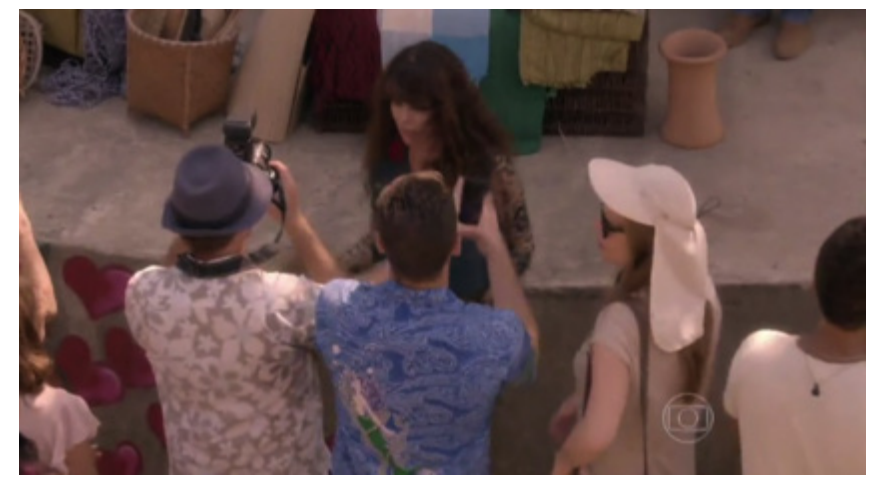

Fig. 10. Estrangeiros visitam a favela (1). Fonte: Gshow

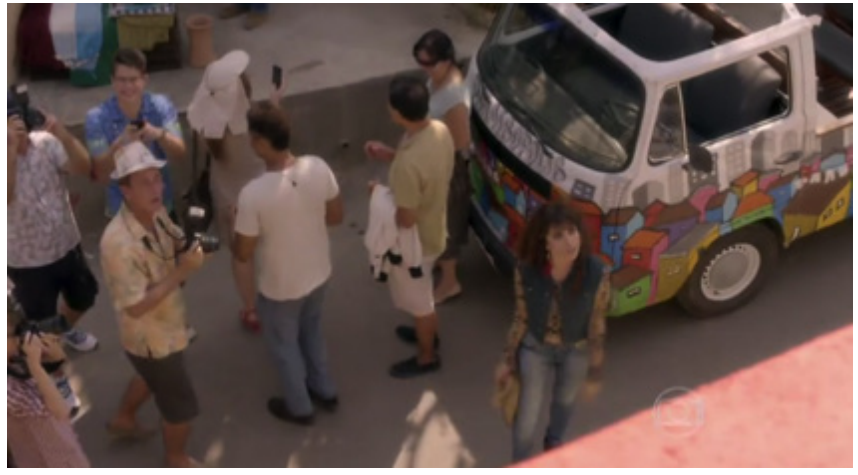

Fig. 11. Estrangeiros visitam a favela (2). Fonte: Gshow

Em seguida, aparecem Danda e Marizete, que se revoltam. A primeira diz: "Fica chamando esses turistas para fotografar a gente como se a gente fosse bicho". Nesse caso, os turistas, ocupando a posição do "Sr. Todo Mundo", visam à admissão, como disse Landowski (ibidem), "em dosagem moderada", isto é, ir à favela, ter contato 
direto com o outro, com o diferente, com uma paisagem exótica, com odores odiosos ${ }^{14}$ para, supostamente, poder voltar ao hotel na zona sul, tomar uma boa ducha e dormir confortavelmente sob um edredom branco e macio, com a temperatura programada para os vinte e poucos graus e, finalmente, voltar ao país de origem. Ao estabelecer a relação entre o favelado/bicho e o estrangeiro/visitante de zoológico, a personagem nega, nesses termos, a admissão do estrangeiro "Sr. Todo Mundo" e afirma a exclusão.

Pelo percurso analítico que se veio traçando nesta seção, nota-se, que, no texto em análise, as formas de lidar com o outro propostas por Landowski (ibidem), apesar de variarem, tendem à admissão: quase sempre a cidade admite a favela; a favela quase sempre admite a cidade. Isso demonstra que, em ambos os casos, nega-se, em geral, a exclusão total (mas também as formas de assimilação total do outro) e permitem-se imbricações e tensões entre cidade e favela, ou seja, entre a identidade e a alteridade.

Por fim, ainda no que diz respeito a como a linguagem visual constrói a relação entre a cidade e a favela, apresentam-se as imagens a seguir (Figs. 12, 13 e 14) ) $^{15}$ :

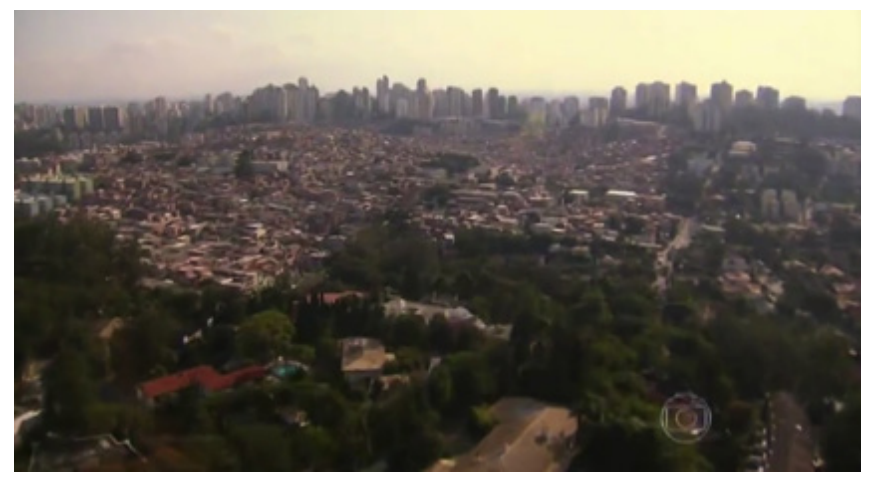

Fig.12. Paraisópolis e a cidade (1). Fonte: Gshow

14 Recorrendo mais uma vez a Landowski (2002, p. 9), o odor do outro é odioso por definição.

15 No que diz respeito à visualidade de Paraisópolis, enunciada pela telenovela em questão, ressalta-se o trabalho de Médola (2016, p. 360) que investiga, por uma perspectiva semiótica, "os modos de visibilidade e construção de visualidades que regem os regimes de interação nas formas de representação televisiva da cidade de São Paulo" no contexto da convergência midiática. Segundo a autora, "a digitalização, a qualidade da imagem, a presença em multitelas, criam visualidades, ou seja, arranjos enunciativos capazes de ressemantizar lugares como a favela/comunidade/bairro de Paraisópolis" (ibidem, p. 362). 


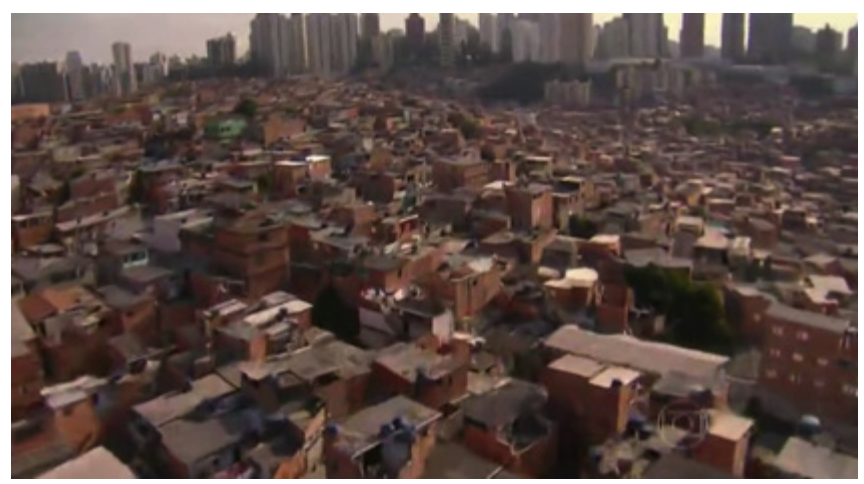

Fig. 13. Paraisópolis e a cidade (2). Fonte: Gshow

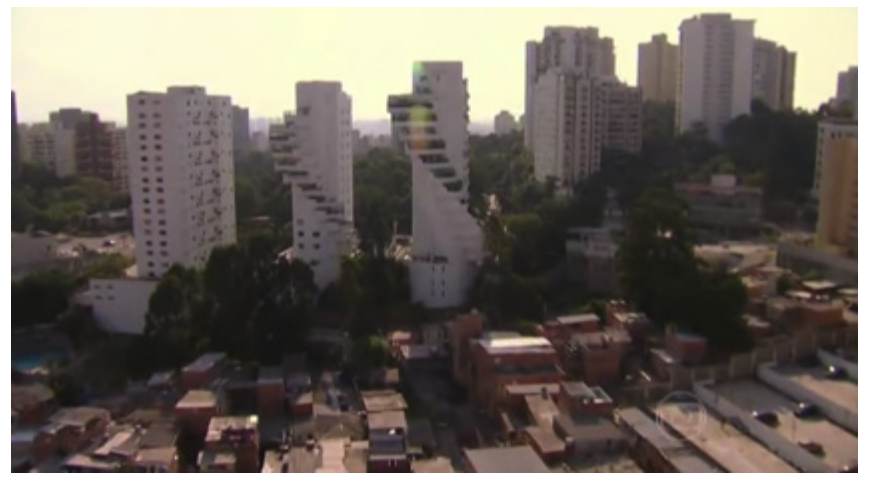

Fig.14. Paraisópolis e a cidade (3). Fonte: Gshow

Assim, levando em conta as figuras 12, 13 e 14, do ponto de vista dos modos de relação com o outro, previstos por Landowski (2002), cidade e favela coexistem na mesma espacialidade sem, no entanto, relacionar-se. Tratar-se-ia de uma forma de segregação, em que essas duas formas de estruturas urbanas não comunicam entre si. Nesse sentido, Oliveira (2013, p. 13), ao tratar das formas de horizontalidade que se opõem à verticalidade dominante na cidade de São Paulo, afirma: “De tanto repetirem-se, as verticalidades acabam se colando uma à outra e formam as densas muralhas separatistas e segregacionistas". Uma dessas formas de horizontalidade tratadas pela autora nesse trabalho é justamente Paraisópolis:

Onde estamos ao olhar esse horizonte de pequenos sobrados, de dois a três andares de tijolos vasados, expondo na sua cor avermelhada da terra o estado de construção a terminar que domina a paisagem? Se ao certo não sabemos nada além de que estamos em algum lugar do alto de Paraisópolis, a muralha vertical 
no horizonte confirma que estamos em São Paulo, a megalópole sul-americana de mais de onze milhões de habitantes (OLIVEIRA, 2013, p. 1).

Considerar-se-á, agora, a homologação entre categorias do plano da expressão com o plano do conteúdo dessas imagens. No que diz respeito ao plano do conteúdo, entende-se que a categoria semântica urbanização vs. desurbanização subsume o texto em questão. No que diz respeito às categorias do plano da expressão, nota-se que a cidade envolve, circunscreve, a favela, de modo que a primeira categoria topológica a ser levada em conta é englobante vs. englobado. Observa-se, ainda, que a favela se distribui espacialmente na horizontal, enquanto a cidade, na vertical. Assim, como segunda categoria topológica, apresenta-se a oposição entre verticalidade vs. horizontalidade. No que diz respeito à categoria cromática, podem-se opor as cores frias (tons de cinza dos edifícios, verde dos espaços arborizados da cidade) às cores quentes e terrosas da favela. Com efeito, para Oliveira (ibidem, p. 4), é justamente a "horizontalidade avermelhada [que] figurativiza [Paraisópolis], como uma mancha espremida" que se opõe à "verticalidade dominantemente alva". No que diz respeito à categoria eidética, observa-se que os edifícios que compõem a cidade possuem forma retangular, enquanto as edificações da favela têm forma quadrangular, de modo que é significativa a oposição retangularidade vs. quadrangularidade. Nesse sentido, afirma Oliveira (ibidem, p. 7):

Distribuindo-se cor e forma distintamente, conforme a configuração geográfica do terreno, essas construções se ladeiam e a paisagem paulistana tanto parece a de encaixes de quadriláteros que espalham a cidade nas brechas da horizontalidade, como também, empilhando horizontal sobre horizontal, a cidade cresce na verticalidade das camadas horizontais constitutivas dos prédios.

Assim, esquematicamente, apresenta-se a homologação entre as categorias do plano do conteúdo e da expressão dos quadros analisados:

\begin{tabular}{|c|c|c|c|c|}
\hline \multirow{2}{*}{$\begin{array}{c}\text { PLANO DO } \\
\text { CONTEUDO }\end{array}$} & \multicolumn{2}{|c|}{ PLANO DA EXPRESSÃO } \\
\cline { 2 - 5 } & Categoria Topológica 1 & Categoria Topológica 2 & Categoria Cromática & Categoria Eidética \\
\hline $\begin{array}{c}\text { Urbanização } \\
\text { (cidade) }\end{array}$ & Englobante & Verticalidade & Cores frias & Retangularidade \\
\hline $\begin{array}{c}\text { Desurbanização } \\
\text { (favela/comunidade) }\end{array}$ & Englobado & Horizontalidade & Cores quentes & Quadrangularidade \\
\hline
\end{tabular}

Tab.1. Homologação entre categorias do plano do conteúdo e da expressão. Fonte: elaboração do autor. 


\section{Considerações finais}

Propôs-se, neste trabalho, compreender como a nova classe média se engendra como discurso em I Love Paraisópolis, entendendo a favela/comunidade como locus de destaque desse grupo social na telenovela em questão.

Para isso, analisaram-se, inicialmente, as estruturas narrativas da apresentação da favela que dá nome à trama. Observou-se que, do ponto de vista narrativo, Paraisópolis se instaura como um actante coletivo, sujeito de estado, virtualizado, que quer, mas não pode. Ao ator do discurso Benjamin, par romântico da protagonista Marizete, corresponde a função actancial de sujeito atualizado que quer, pode e sabe realizar a performance "reurbanizar Paraisópolis". Ideologicamente, repercute o fato de que a própria favela/ comunidade não é capaz de realizar essa tarefa, cabendo a um outro sujeito, figurativizado pelo jovem, branco, da elite, morador do Morumbi, fazê-lo.

No que diz respeito ao nível discursivo, observou-se que os percursos temáticofigurativos que se ligam à ideia de nova classe média são o do consumo e, em menor grau, o da educação. Assim, ascende-se socialmente e, com isso, passa a haver um alargamento do horizonte simbólico desse grupo, elementos que constituem algumas práticas semióticas da chamada nova classe $C$.

Finalmente, foram objeto de análise as relações entre identidade e alteridade, considerando-se as tensões e imbricações entre cidade e favela. Observou-se que a relação que prevalece é a da admissão, tanto do ponto de vista da cidade em relação à favela quanto do contrário. Ainda, pela análise da visualidade, constatou-se que, apesar da segregação (que é a negação da assimilação) em que cidade e favela coexistem sem se comunicar, as interações sociais permitem outras práticas como as de admissão (que é a negação da exclusão) aqui demonstradas.

Assim, com base nas análises empreendidas, é possível, então, reconstituir essa nova classe média, como efeito de sentido, na telenovela I Love Paraisópolis: narrativamente, instaura-se como sujeito do estado (o que repercute em termos ideológicos, como se frisou); discursivamente, liga-se aos temas do consumo e da educação (ainda que este último seja em menor grau); no que diz respeito aos modos como essa nova classe média se relaciona com a alteridade, prevalece o regime da admissão. Assim, como se mencionou, se o método de análise semiótica parte sempre do texto, a partir dele, é possível chegar ao contexto (BARROS, 2002), ao social, em suma, à relação entre homem e sociedade.

Conrado Moreira Mendes é professor do Programa de Pós-graduação stricto sensu em Comunicação Social da PUCMG. É doutor em Semiótica e Linguística Geral pela USP.

conradomendes@yahoo.com.br 


\section{Referências}

BARROS, D. Intolerância, preconceito e exclusão. In: LARA, G.; LIMBERTI, R. (Orgs.) Discurso e (des)igualdade social. São Paulo: Contexto, 2015.

Teoria do discurso: fundamentos semióticos. 3a ed. São Paulo: Humanitas / FFLCH / USP, 2002.

BEIVIDAS, W. Reflexões sobre o conceito de imanência em semiótica. Por uma epistemologia discursiva. CASA. Cadernos de Semiótica Aplicada, v. 6, p. 1-13, 2008.

Reflexões sobre o discurso: a linguagem como re-criação do mundo. In: LARA, G. (Org.). Lingua(gem), texto, discurso. Entre a reflexão e a prática. Rio de Janeiro: Lucerna; Belo Horizonte: FALE/UFMG, 2006.

BRASIL. Secretaria de Assuntos Estratégicos (SAE). Vozes da classe média. Brasília, 2012a, Disponível em: <http://www.sae.gov.br/site/wp-content/uploads/Cartilha-Vozes-Classe-Media.pdf >. Acesso em 15 Ago. 2015.

. Vozes da classe média. Caderno 2. Brasília, 2012b. Disponível em: <http://www.sae.gov.br/ vozesdaclassemedia/wp-content/uploads/Vozes-da-Classe-Media-2\%C2\%BA-Caderno.pdf>. Acesso em 15 ago. 2015.

CHIARA, M.; PAPP, A. C. Crise joga 3 milhões de famílias da Classe $C$ de volta à base da pirâmide. O Estado de S. Paulo. São Paulo, 31 out. 2015. Disponível em: <http://economia.estadao. com.br/noticias/mercados, crise-joga-3-milhoes-de-familias-da-classec-de-volta-a-base-dapiramide,1789248> Acesso em 25 Mai. 2016.

FIORIN, J. L. Elementos de análise do discurso. 14 ed. São Paulo: Contexto, 2006.

As astúcias da enunciação: as categorias de pessoa, espaço e tempo. 2 ed. São Paulo: Ática, 2005a. Linguagem e ideologia. 8 ed. São Paulo: Ática, 2005b.

FRANÇA, V. R.; CORRÊA, L. Apresentação. In: Mídia, instituições e valores. (Org.).

Belo Horizonte: Autêntica, 2012.

GREIMAS, A.; COURTÉS, J. Dicionário de semiótica. São Paulo: Contexto, 2008.

GREIMAS, A.; LANDOWSKI, E. Analyse sémiotique d'un discours juridique. In: GREIMAS, A. Sémiotique et sciences sociales. Paris: Seuil, 1976, p. 96-99.

HOUAISS, A.; VILLAR, M. Dicionário Houaiss da língua portuguesa. Rio de Janeiro: Objetiva, 2001.

HUPPES, I. Melodrama: gênero e sua permanência. São Paulo: Ateliê Editorial, 2000.

I LOVE PARAISÓPOLIS. $1^{\circ}$ Capítulo. Direção: Wolf Maya e Carlos Araújo. Rio de Janeiro: Rede Globo de Televisão, 2015. 44 min. HDTV. Disponível em: <http://gshow.globo.com/novelas/i-loveparaisopolis/>. Acesso em 15 Jul. 2016.

LANDOWSKI, E. Presenças do outro: ensaios de sociossemiótica. São Paulo: Perspectiva, 2002.

MAURO, R. Aspectos da midiatização do consumo e do sentido de classe social na telenovela: a representação da nova classe C. 159 p. Dissertação de Mestrado. Universidade de São Paulo, Escola de Comunicação e Artes, 2014.

MÉDOLA, A. Visibilidade, Visualidade e regimes de interação na era da televisão ubíqua: representações de São Paulo na televisão aberta brasileira. In: XIII Congreso Latinoamericano de Investigadores de la Comunicación, 2016, México. Memorias XIII Congreso Latinoamericano de Investigadores de la Comunicación. Sociedad de Conocimiento y Comunicación. México: ALAIC, 2016. v. 1. p. 359-364. 
NERI, M. A nova classe média: o lado brilhante da base da pirâmide. São Paulo: Saraiva, 2011.

OLIVEIRA, A. C. Interação e sentido nas práticas de vida. Comunicação, mídia e consumo, v. 11, p. 179-198, 2014.

Brechas da horizontalidade na muralha vertical de São Paulo. Caderno de Discussão do Centro de Pesquisas Sociossemióticas (Cd-Rom), v. 1, p. 1-17, 2013.

POCHMANN, M. Nova classe média? O trabalho na base da pirâmide social brasileira. São Paulo: Boitempo, 2012.

SOUZA, J. Os batalhadores brasileiros: nova classe média ou nova classe trabalhadora. Belo Horizonte: Editora UFMG, 2010.

THOMASSEAU, J. O melodrama. Tradução de C. Braga; J. Penjon. São Paulo: Perspectiva, 2005, p. 36.

ZILBERBERG, C. Elementos de semiótica tensiva. Tradução de I. C. Lopes, L. Tatit e W. Beividas. São Paulo: Ateliê Editorial, 2011.

Artigo recebido em abril e aprovado em julho de 2017. 